\title{
Yanfeng calcined dolomite two-step preparation of calcium magnesium sand
}

\author{
Wangnian Zhang, Ning Deng, Weijie Liang, Llli Peng, Zhao Xin \\ Jiujiang University, College in mechanical engineering and material, Jiujiang, Jiangxi Province \\ zwn2003@126.com
}

Keywords: Calcium magnesium dolomite, two-step calcining, preparation technology Abstract. In this paper the influence of beforehand condition and sinter degree to capability of sintered dolomite has been investigated by means of measure actived degree and capability of high temperature sintered and property of resist hydrate of different material granularity after different beforehand sinter degree.Ascertain the activate of dolomite is the best when the beforedhand sinter degree is $850^{\circ} \mathrm{C}$. The beforehand sinter time is 3 hours. And the sinter degree is $1650^{\circ} \mathrm{C}$. The material bulk-density reach 3.2 $\mathrm{g} / \mathrm{cm}^{3}$ and the cability of resist hydrate reach $2.1 \%$. when dolomite are preparted on this condition.

\section{Introduction}

$\mathrm{MgO}-\mathrm{CaO}$ refractory with good thermal stability, resistance to corrosion and strong basic slag and unique ability to purify molten steel is steel smelting characteristics, especially high-quality clean steel refractory, has been attracting much attention at home and abroad, high-performance refractory.

But its reaction with water resulting in volume expansion, product powder, severely limiting the promotion and application of magnesium and calcium-based material, thereby increasing the ability of anti-hydration calcium magnesium-based material can be the key to this material widely applied ${ }^{[1]}$. Magnesium and calcium-based material on the anti-hydration problems, people do a lot of research, usually the main methods are: high-temperature sintering method, an impurity is added, surface overlay and vacuum packaging method, etc. These methods of magnesium and calcium-based material anti-hydration capacity there are some positive effect. But the anti-hydration effect on the performance and the impact of raw steel liquid pollution aspects into account, magnesium and calcium-based material surface modification of these methods is undoubtedly the most promising one.

\section{Test}

The raw material. Natural dolomite chemical composition and XRD spectra are shown in table 1 and figure 1. It can be seen that the dolomite are litter impurity, high purity, main phase are $\mathrm{CaMg}\left(\mathrm{CO}_{3}\right)_{2}$, containing a small amount of $\mathrm{CaCO}_{3}$, few impurities, preparation of high quality calcium magnesium sand can be used as a raw material.

Table 1 Chemical compositions of dolomite ( \%)

\begin{tabular}{cccccc}
\hline $\mathrm{SiO}_{2}$ & $\mathrm{Al}_{2} \mathrm{O}_{3}$ & $\mathrm{Fe}_{2} \mathrm{O}_{3}$ & $\mathrm{CaO}$ & $\mathrm{MgO}$ & $\mathrm{IL}$ \\
\hline 0.19 & 0.21 & 0.11 & 31.90 & 20.52 & 46.20 \\
\hline
\end{tabular}

Test procedure. Dolomite was crushed to $0.088 \mathrm{~mm}$ sieve and light burned form $750{ }^{\circ} \mathrm{C}$ to $1000{ }^{\circ} \mathrm{C}$ for 3 hours. To study the effect of temperature on light burning sintering properties and hydration resistance, and then pressed into $\Phi 20 \mathrm{~mm} \times 20 \mathrm{~mm}$ sample cores from the silicon molybdenum rod furnace electric furnace at $1650{ }^{\circ} \mathrm{C} \times 3 \mathrm{~h}$ calcination, sintering and sinter detect performance testing.

Sintering temperature test: According to the previous results ${ }^{\lceil 2\rfloor}$, choose the best light burning conditions after sample preparation, through different sintering temperature silicon molybdenum rod furnace electric furnace calcination, sintering temperature is selected as $1550{ }^{\circ} \mathrm{C}, 1600{ }^{\circ} \mathrm{C}, 1650{ }^{\circ} \mathrm{C}$, $1700{ }^{\circ} \mathrm{C}$.

Test procedure.Light burning activity detection: Press YB/T 105-1997 detect light burning degree of activity $^{\lceil 3\rfloor}$. 
High temperature sintering performance testing: Press YB / T5200-93 of porosity and bulk density of the sample for testing

Hydration resistance test: anti hydration test method using autoclave sinter crushing of $2 \sim 3 \mathrm{~mm}$, placed in a beaker. Water was added into the autoclave, sealed, and heated to a pressure in the autoclave reached $0.15 \mathrm{MPa}$ nowadays packing $2 \mathrm{~h}$, and then drying the sample and measuring the powdering ratio and the quality of the sample rate of increase ${ }^{[4\rfloor}$.

$$
\begin{aligned}
& \text { Quality increase rate }=\frac{\mathrm{m}_{2}-\mathrm{m}_{1}}{\mathrm{~m}_{1}} * 100 \\
& \text { Pulverization rate }=\frac{\mathrm{m}_{3}-\mathrm{m}_{1}}{\mathrm{~m}_{1}} * 100
\end{aligned}
$$

Type: $\mathrm{m}_{1}$ for sample before hydration quality, $\mathrm{g} ; \mathrm{m}_{2}$ for sample after hydration quality, $\mathrm{g} ; \mathrm{m}_{3}$ for sample after hydration after $1 \mathrm{~mm}$ sieve feeding of dry weight, $\mathrm{g}$.

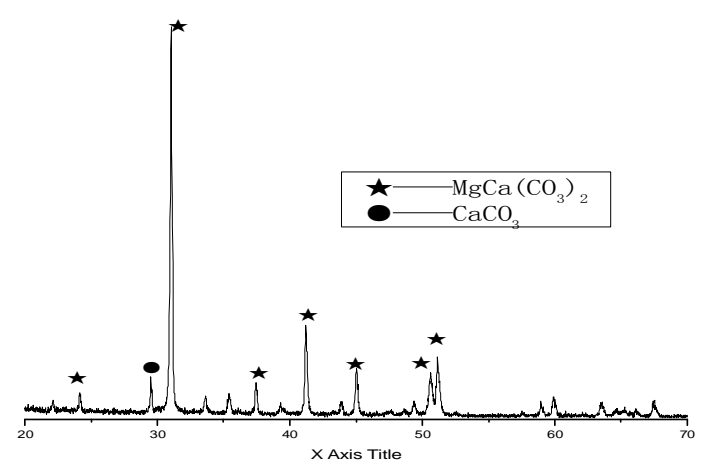

Fig1 XRD pattern of dolomite

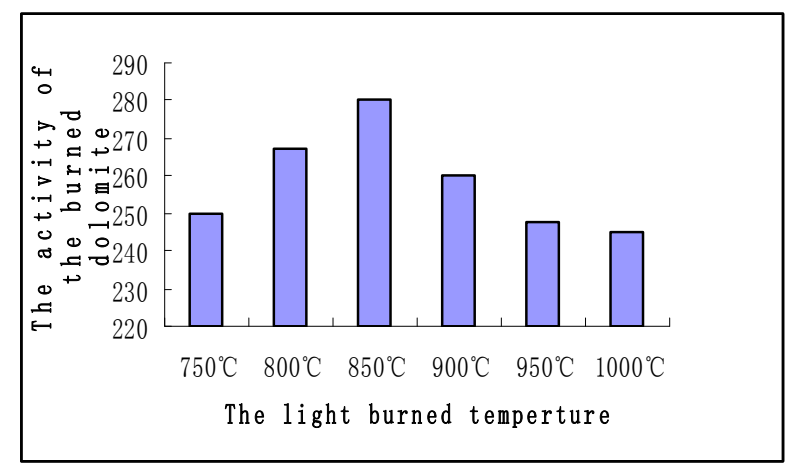

Fig2 Activity of light burned dolomite $v s$ light burning temperature

\section{Results and discussion}

The influence of light burning temperature.Figure 2 shows that, with the light burning temperature increased, the activity of the material decreased, the activity of the dolomite reach to highest when the light burning temperature was $850^{\circ} \mathrm{C}$.

Figure 3 shows the relationship material after calcination bulk density and porosity between the temperature and the light burned.

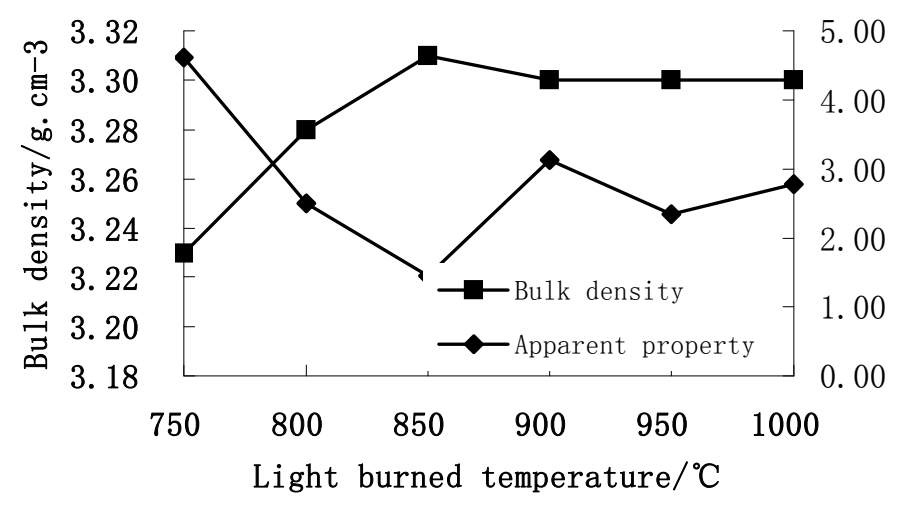

Fig3 Bulk-density and pore-rate of different beforehand degree dolomite after sintered

It can be seen from Figure 3, the bulk density of the sintered dolomite rises with the light burning temperature rises, the bulk density of the maximum density and volume when light burned temperature was $850^{\circ} \mathrm{C}$. This is because the light burning temperature is low, dolomite not burn through, the activity is not enough, after sintering components uneven impact of its high-temperature calcination dolomite bulk density and porosity. But light burning temperature is too high, break out the activity at 
low temperatures $\mathrm{CaO}, \mathrm{MgO}$ development will grow, thereby reducing its activity, leading to lower material sintering properties.

The relation ship of the dolomite hydration property and light temperature are shown Figure 4.

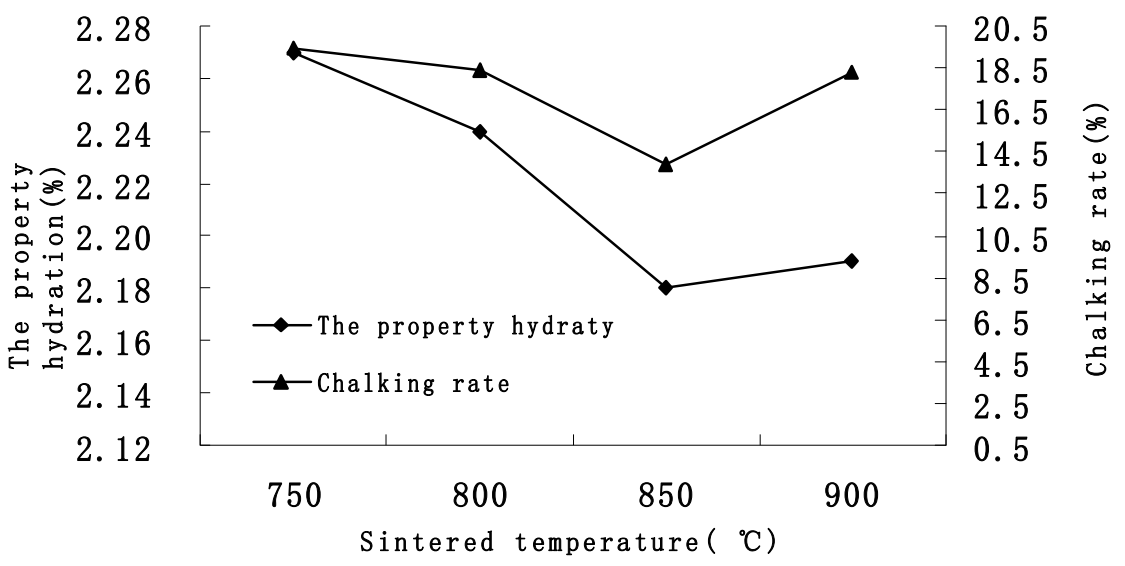

Fig 4 Property of resist hydrate and the rate pulverization of different beforehand degree dolomite after sintered

As can be seen from Figure 4, the property of hydration resistance and light burning at different temperatures digestion quality growth rate, bulk density, porosity consistent variation that light burning temperature is at $850{ }^{\circ} \mathrm{C}$ its best hydration resistance, chalking the lowest rate.

Study on sintering temperature.Figure 5 shows the influence of sintering temperature on the performance of sintered dolomite.

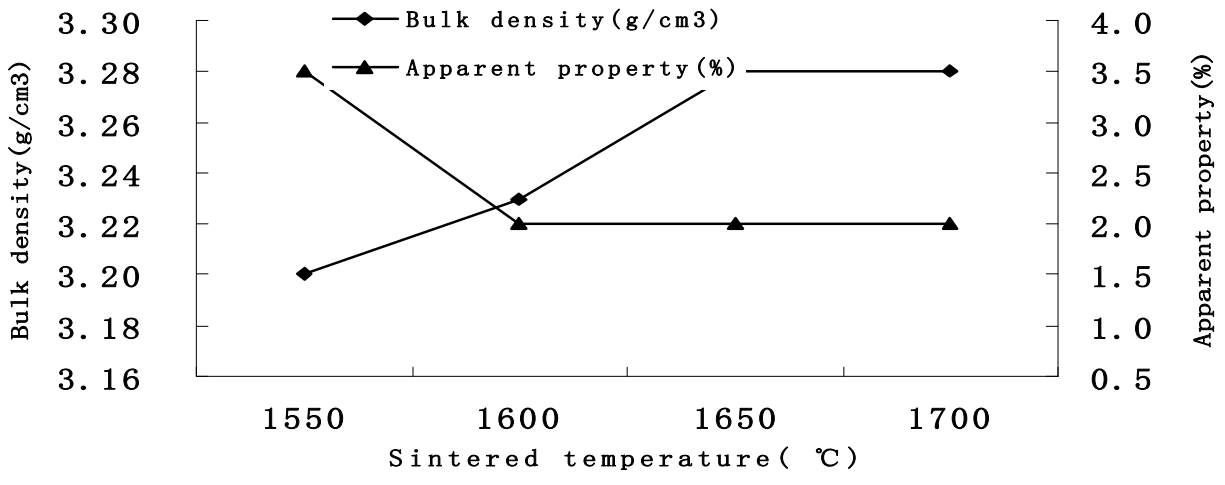

Fig 5 Bulk-density of dolomite after sintered

It can be seen from Figure 5, with the sintering temperature, magnesium and calcium dolomite sand bulk density increases, the porosity decreased. Sintering temperature at $1500{ }^{\circ} \mathrm{C}$ bulk density small sample not fully sintered. When the sintering temperature is $1600{ }^{\circ} \mathrm{C}, 1650{ }^{\circ} \mathrm{C}$, the volume density of the sample increases considerably larger, the sintering temperature from $1650{ }^{\circ} \mathrm{C}$ to $1700{ }^{\circ} \mathrm{C}$, the volume density of the pattern of change is not large. Thus, dolomite in sintering temperature is $1650{ }^{\circ} \mathrm{C}$ can be very dense sintering. Temperature rises again, it plays densification of effect is not very obvious.

Figure 6 is a calcium magnesium dolomite sand prepared hydration resistance to sintering temperature relationship. 


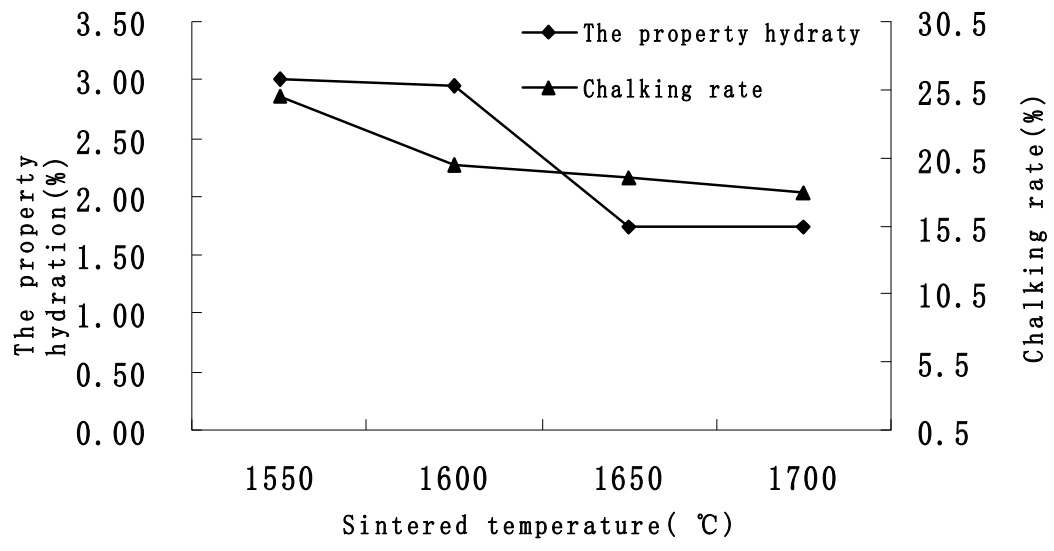

Fig 6 The property hydrate and the rate pulverization of different degree dolomite after sintered

As can be seen from Figure 6, when the sintering temperature is $1550{ }^{\circ} \mathrm{C}$, calcium magnesium dolomite sand prepared hydration resistance weight gain and large, chalking rates are also high. However, with the sintering temperature, weight gain and powdering rate decreased, especially by the sintering temperature was raised to $1600{ }^{\circ} \mathrm{C} 1650{ }^{\circ} \mathrm{C}$, the anti-hydration rate decreased weight gain is obvious, the sintering temperature is increased from $1650{ }^{\circ} \mathrm{C}$ to $1700{ }^{\circ} \mathrm{C}$, did not change significantly. Visible sintering temperature at $1600{ }^{\circ} \mathrm{C}$ to $1650{ }^{\circ} \mathrm{C}$, the sintering performance of great change dolomite, sintering was also very dense, and its hydration resistance also been greatly improved.

Figure 7 is an enlarged dolomite different sintering temperatures 5000 times SEM image, A sintering temperature is $1550{ }^{\circ} \mathrm{C}$; B sintering temperature was $1600{ }^{\circ} \mathrm{C}$; $\mathrm{C}$ sintering temperature is $1650{ }^{\circ} \mathrm{C}$; D sintering temperature was $1700{ }^{\circ} \mathrm{C}$.
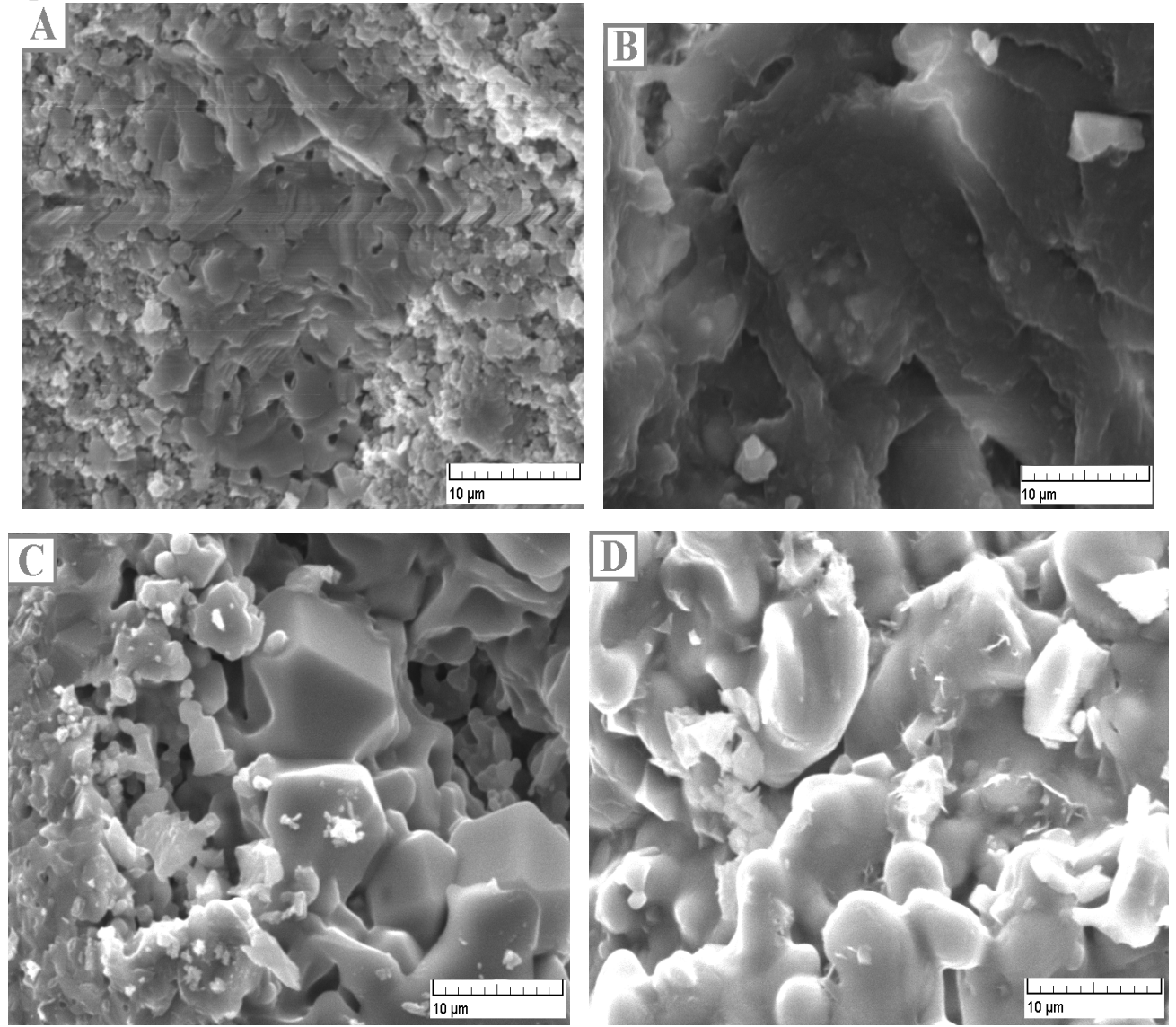

$\left(\mathrm{A}-1500^{\circ} \mathrm{C} ; \mathrm{B}-1550^{\circ} \mathrm{C} ; \mathrm{C}-1650^{\circ} \mathrm{C} ; \mathrm{D}-1700^{\circ} \mathrm{C}\right)$

Fig 7 SEM of different temperature sintered dolomite 
As can be seen from Figure 7, the sintering temperature is $1550{ }^{\circ} \mathrm{C}$, the synthetic calcium magnesium sand volume density, porosity is also high. But with the sintering temperature, grain growing up, having a diameter of about $3.3 \mu \mathrm{m}$ grain grows to a diameter of about $10 \mu \mathrm{m}$. Bulk density increases, the porosity decreases. Sintering temperature at $1600{ }^{\circ} \mathrm{C}$ to $1650{ }^{\circ} \mathrm{C}$, the sintering performance changes synthetic calcium magnesium sand large, sintering was also very dense, and its porosity also been greatly reduced.

\section{Conclusion}

Through this experimental work, it is considered the best preparation Yanfeng Dolomite light burning magnesium and calcium sand temperature was $850{ }^{\circ} \mathrm{C}$, light burn time of 3 hours, the sintering temperature is $1650{ }^{\circ} \mathrm{C}$.

\section{Acknowledgements}

The research projects of Jiujiang University, Item Number: 8651709;

The research projects of Jiujiang University, Item Number: 8651809;

The research projects of Jiujiang University, Item Number: 8400209

\section{References}

[1] Xiuying Zhu. Shouye Wong. Light burned dolomite hydration performance research [J]. Journal of refractory materials, 1990 (3): 23 and 24.

[2] Wei Liu. High. Calcium and magnesium sand quality synthesis technology research and application of anti-hydration[D]. Wuhan: wuhan university of science and technology. 2004:54 and 55.

[3] WeiLiu, Yonghe Liang, Yunyun $\mathrm{Wu}$. Calcium and magnesium sand quality synthesis technology research and application of anti-hydration[J]. Journal of wuhan university of science and technology, 2001(9): 45-47.

[4] Junyin $\mathrm{Wu}$.The second step synthesis method of calcium magnesium sand burning research [J]. Journal of gansu metallurgy, 2007, 29 (6): 20-23. 